\title{
RECEITAS A SEREM SEGUIDAS? MAPEAMENTO SOBRE O FENÔMENO "EMPREENDEDORISMO DE PALCO" EM REPORTAGENS DA WEB
}

\author{
Are you following recipes? Mapping about the phenomenon \\ "entrepreneurship on stage" in web reports
}

Lauriene Teixeira Santos

E-mail: lauriene.tsantos@gmail.com

Graduada em Administração pelo Instituto Federal de Minas Gerais-Campus Bambuí; Mestranda em Administração no Departamento de Administração e Economia da Universidade Federal de

Lavras; Pesquisadora (Capes).

Endereço para contato: Aquenta Sol, Lavras, 37200-900, Minas Gerais, Brasil.

https://orcid.org/0000-0002-8281-9057

Juliana de Oliveira Becheri

E-mail: julianabecheri@gmail.com

Graduada em Administração pela FAI-Centro de Ensino Superior em Gestão, Tecnologia e

Educação; Mestranda em Administração no Departamento de Administração e Economia da

Universidade Federal de Lavras; Pesquisadora (Capes).

https://orcid.org/0000-0002-2404-6535

Izadora Ribeiro e Garcia de Oliveira

E-mail: izadora_rgo@hotmail.com

Graduada em Administração Pública pela Universidade Federal de Lavras; Mestranda em Administração no Departamento de Administração e Economia da Universidade Federal de Lavras;

Pesquisadora (CNPq). https://orcid.org/0000-0003-4562-379X

Paulo Henrique Montagnana Vicente Leme E-mail: paulo.leme@ufla.br

Doutor em Administração pela Universidade Federal de Lavras; Mestre em Administração pela Universidade Federal de Lavras; Professor no Curso de Administração do Departamento de Administração e Economia da Universidade Federal de Lavras. https://orcid.org/0000-0003-4174-5642

Artigo recebido em 5 de fevereiro de 2020. Aceito em 17 de junho de 2020. 


\section{Resumo}

Os estudos e pesquisas a respeito do empreendedorismo têm crescido ao longo do tempo. Contudo, o interesse sobre esse tema vai além do meio acadêmico, estendendo-se para a mídia de negócios. Assim, é possível verificar o surgimento do fenômeno "empreendedorismo de palco", que recentemente tem ganhado espaço no mundo dos negócios. O objetivo geral do presente artigo é mapear, por meio de reportagens divulgadas na internet, em sites brasileiros, o que tem sido abordado sobre esse fenômeno. Espera-se que ao analisar o conteúdo dessas reportagens seja possível obter dados relevantes para fomentar uma discussão a respeito dessa temática. $O$ estudo apresenta uma abordagem qualitativa e exploratória. Como técnica de análise dos dados, utilizou-se a análise de conteúdo, sob os preceitos de Bardin. Os resultados obtidos são apresentados e discutidos de acordo com as categorias de análise: definições sobre empreendedorismo de palco; falsas promessas; empreendedorismo como autoajuda; indústria do sonho; e foco voltado para ferramentas concretas. Assim, identificou-se que a abordagem das reportagens está voltada para um alerta aos leitores sobre o conteúdo difundido mediante o "empreendedorismo de palco", mostrando que há um grande apelo motivacional, em detrimento de conceitos e práticas com embasamento teórico-científico. Nesse sentido, percebe-se que por intermédio do "empreendedorismo de palco" ideias equivocadas têm sido difundidas a respeito do empreendedorismo, pois este apresenta "receitas prontas" indicando que com o devido esforço os objetivos almejados são alcançados. Apresenta então, a ideia que uma mesma configuração serve para todas as pessoas e empresas.

Palavras-chave: Empreendedorismo. Empreendedorismo de palco. Reportagens da web.

\section{Abstract}

Studies and research on respect for entrepreneurship have increased over time. However, the interest on this topic goes beyond the academic environment, appearing in the business media. Thus, it is possible to verify the phenomenon "entrepreneurship on stage", which recently gained space in the business world. The general objective of this article is to map through reports released on the internet, on Brazilian websites, reports that have been addressed about this phenomenon. It is expected that when analyzing the content of these reports, it will be possible to obtain relevant data to encourage a discussion on the respect of this theme. The study presents a qualitative and exploratory approach. As a data analysis technique, use content analysis, under Bardin's precepts. The results presented are discussed according to the categories of analysis: definitions of stage entrepreneurship; fake promises; entrepreneurship as self-help; dream industry; focus on concrete tools. Thus, it was identified that the reporting approach is aimed at alerting readers about the widespread content of entrepreneurship, showing that there is a great motivational appeal, to the detriment of concepts and practices with theoretical-scientific basis. In this sense, it is clear that, through "entrepreneurship on stage", ideas are misunderstood in terms of respect for entrepreneurship, as it presents "readymade recipes" that show how suffering is, the desired goals that are achieved. It then presents an idea that the same configuration is suitable for all people and companies.

Keywords: Entrepreneurship. "Entrepreneurship on stage". Web reports.

\section{INTRODUÇÃO}

O empreendedorismo é um tema promissor, que se encontra em plena ascensão (Tonelli, Brito, \& Zambalde, 2011). Todavia, não é apenas no campo científico que o 
empreendedorismo tem despertado interesse. A mídia de negócios tem voltado sua atenção para o tema, procurando compreender quem seria o empreendedor e como esse fenômeno ajuda a potencializar carreiras (Costa, Barros, \& Martins, 2012).

Nos últimos anos, percebeu-se um aumento considerável da mídia de negócios, em que livros, revistas e afins estão entre os mais vendidos e populares (Costa et al., 2012). Collins (2012) retrata que foi a partir da década de 1980 que os textos gerenciais passaram a atrair um público significativo, ocupando lugar de proeminência nas listas do mais vendidos nos Estados Unidos e Reino Unido.

É preciso ressaltar que esse tipo de discurso nunca esteve vinculado estritamente à área teórica, existindo, ainda, uma abertura para que se despreze o conhecimento originado na academia, com a intenção de que esse ramo adquirisse o status de setor de negócios (Carvalho, Carvalho, \& Bezerra, 2010), o que pode favorecer o populismo, e, consequentemente, a vulgaridade do conhecimento (Collins, 2012).

Se de um lado existe a mídia de negócios, buscando vender os discursos contidos em seus aparatos, na outra ponta se encontram profissionais inseridos dentro de um mercado de trabalho exigente e mutável, que passa por frequentes enxugamentos, demissões e terceirizações (Carvalho et al., 2010). Assim, há uma impressão permanente de que todo conhecimento está fadado a ficar desatualizado, principalmente na área de negócios de um mundo globalizado (Carvalho et al., 2010).

Nesse contexto surge o "empreendedorismo de palco", no qual pessoas com boa oratória cativam o público sob a pretensão de agregar novos conhecimentos, porém, em grande parte dos casos, sem possuir uma vivência profissional e não agregando nada além de frases de efeito e ideias vazias (Santos \& Freitas, 2017).

Entende-se que todo esse processo pode adquirir contornos ideológicos quando é inserido em um contexto em que há uma valorização de "receitas prontas", contribuindo, então, para que haja uma homogeneização de conceitos e práticas, além da propagação da imagem de profissionais idealizados (Costa et al., 2012). Assim, surge o tipo ideal do empreendedor, como um herói emblemático, que se atreve a enveredar por novos caminhos (Costa et al., 2012).

Diante do exposto, o presente estudo busca responder à seguinte pergunta: o que tem sido abordado sobre o fenômeno "empreendedorismo de palco" nas reportagens divulgadas na internet através de sites brasileiros? Dessa forma, o objetivo geral do presente artigo é mapear, por meio de reportagens divulgadas na internet, em sites brasileiros, o que tem sido abordado sobre o fenômeno do "empreendedorismo de palco". Para tanto, estabelecem-se os seguintes objetivos específicos: identificar as reportagens sobre o tema "empreendedorismo de palco"; realizar a categorização das reportagens identificadas; mapear as discussões sobre o fenômeno do "empreendedorismo de palco". 
Justifica-se a realização do presente estudo, visto que o conteúdo de reportagens divulgadas na web é uma poderosa fonte de dados que podem ser convertidos em interessantes e válidas informações (Galvão \& Marin, 2009). Além disso, a justificação para a realização do presente estudo se concentra no fato de que o fenômeno do "empreendedorismo de palco" pode ter sua expressividade aumentada pelo alcance da internet. Assim, torna-se relevante entender como isso tem sido tratado em veículos de comunicação que atingem grande parte da população brasileira. Ademais, os resultados desta pesquisa podem trazer contribuições em variadas vertentes: social, acadêmica e gerencial, uma vez que a temática é atual e seus efeitos são percebidos na sociedade contemporânea.

A originalidade da pesquisa se concentra em identificar como o fenômeno "empreendedorismo de palco" tem sido retratado pela mídia de negócios por meio de reportagens difundidas em sites brasileiros. Dessa forma, a pesquisa se apresenta como uma sondagem das percepções difundidas a respeito desse fenômeno, levando em consideração a abrangência e a facilidade de acesso das reportagens publicadas na internet.

\section{FUNDAMENTAÇÃO TEÓRICA}

A fundamentação teórica do presente artigo buscou apresentar discussões acerca da figura do empreendedor e do que seria o fenômeno "empreendedorismo de palco".

\subsection{A FIGURA DO EMPREENDEDOR}

Desde a antiguidade existem pessoas que se destacam em suas atividades, buscando inová-las para a obtenção de melhores resultados (Brito, Pereira, \& Linard, 2013). Por trás dessa busca pelo aperfeiçoamento e criação de novidades, encontram-se os indivíduos responsáveis pelas grandes mudanças que revolucionaram o estilo de vida das pessoas no século XX (Dornelas, 2008).

Denominados empreendedores, atualmente estes são objeto de estudo de variadas pesquisas graças ao reconhecimento de sua importância para o desenvolvimento econômico e da inovação. Como afirma Dornelas (2008) "uma vez que os empreendedores estão revolucionando o mundo, seu comportamento e o próprio processo empreendedor devem ser estudados e entendidos" (p. 5).

Não há uma única definição universal para o empreendedor. De acordo com Chiavenato (2012), a personalidade empreendedora exibe traços associados ao empreendedorismo, assim, a literatura é vasta e aponta para variadas direções. Tendo isso em vista, neste 
trabalho, o empreendedor será retratado a partir dos principais momentos em que ele foi estudado por pesquisadores, como também apreciado ou defendido pela sociedade.

Desse modo, pode-se entender que um dos momentos cruciais para a afirmação da importância da figura do empreendedor foi assentado sob a premissa de que a inserção de novas empresas e a manutenção de suas atividades eram um elo fundamental para - crescimento e a sustentação da sociedade moderna. Essa importância começou a ser assinalada pelo economista Jean-Baptiste Say que enfatizava a relevância do empreendedor para o bom funcionamento econômico (Portier \& Tiran, 2009).

Em 1942, Schumpeter conseguiu disseminar de forma mais abrangente a importância do empreendedor por meio da Teoria da Destruição Criativa, afirmando que o empreendedor era essencial para manter as atividades econômicas do Estado em pleno funcionamento. O empreendedor, então, passou a ser visto como fruto da sociedade capitalista moderna, e, em razão do contraste dessa sociedade com o tradicionalismo, o empreendedor, por vezes, foi transformado em herói (Martes, 2010). Nesse sentido, quem adapta e administra eficientemente uma organização não pode ser considerado empreendedor, pois não rompeu com a barreira entre a inovação e o tradicional/institucionalizado (Martes, 2010).

Autores como McClelland (1972) procuraram observar o lado comportamental do empreendedor, uma vez que os traços da personalidade desses indivíduos, e, principalmente sua motivação, poderiam justificar o desenvolvimento das nações. Segundo McClelland os três fatores que impactam o comportamento do empreendedor são: a necessidade de realização alinhada com algumas características pessoais, como: persistência e predisposição ao risco; necessidade de afiliação; e atributos relacionados à independência, autoconfiança, persuasão, entre outros.

De acordo Franco e Gouvêa (2016) os autores do enfoque comportamental enfatizam as características próprias do indivíduo para entender e explicar o perfil empreendedor, uma vez que se baseiam nelas para distinguir esses indivíduos do resto da população. Ainda nesse período surge uma nova vertente: a sociológica. Nessa abordagem os empreendedores influenciam e são influenciados pela sociedade da qual fazem parte (Franco \& Gouvêa, 2016).

Outra perspectiva a respeito do empreendedorismo são os estudos gerenciais (Franco \& Gouvêa, 2016). Nesse sentido, é possível mencionar os estudos de Drucker (1985), que buscou compreender as capacidades de gestão e a postura empreendedora após a empresa estar em funcionamento. Gartner (1985) também se destaca ao propor que o empreendedorismo se configura por meio de um processo, em que este deve ser estudado ao longo de um período de tempo.

Contudo, cabe destacar que os estudos a respeito do empreendedorismo se configuram mediante fases histórico-científicas, sendo que estas não possuem clara delimitação temporal 
e se encontram relacionadas (Baron \& Shane, 2007). Assim, é possível dizer que o estudo do empreendedorismo e do empreender sofre variações ao longo do tempo e conforme a abordagem utilizada.

Ainda assim, Szeman (2015) defende que o mundo em que vivemos confere um valor inquestionável ao empreendedorismo, no qual este molda políticas públicas, desenvolvimento social, crenças culturais e aspectos econômicos. Com esse ideário em mente, ao longo dos anos, ações privadas foram desenvolvidas a fim de garantirem um ambiente propício para o lócus do empreendedorismo e políticas públicas foram desenhadas e implementadas com essa mesma finalidade.

No Brasil, a figura empreendedora começou a se destacar somente a partir de 1990 com a criação do Serviço Brasileiro de Apoio às Pequenas e Médias Empresas (Sebrae), por meio de políticas públicas como: o Empretec e o Jovem Empreendedor (Dornelas, 2005). Em 2017, de acordo com a pesquisa do Global Entrepreneurship Monitor (GEM) cerca de 50 milhões de brasileiros empreendem ou já agiram (no ano da realização da pesquisa) para a criação de um empreendimento em um futuro próximo.

Fatores como as características intrínsecas da população brasileira (diversidade étnica e cultural), poucas barreiras para abertura de novos negócios e amplo acesso à informação e conteúdo a respeito do empreendedorismo disponível na internet têm contribuído para a afirmação da figura do empreendedor (Global Entrepreneurship Monitor [GEM], 2015, 2017). Assim, com um ambiente mais propício à figura do empreendedor, outras profissões, especialmente coachings e consultores tiveram sua demanda dobrada. Esse aumento de demanda favoreceu que indivíduos, atualmente reconhecidos como "empreendedores de palco", também vendessem produtos, serviços e ideias para quem quisesse se tornar um empreendedor ou procurasse melhorar seu desempenho no mundo dos negócios.

De forma mais específica, o termo "empreendedor de palco" se refere aos palestrantes motivacionais que se voltam ao público empreendedor (Faria, 2018). Contudo, em muitos dos casos, os "empreendedores de palco" não têm conteúdo a agregar (Faria, 2018), e, assim, utilizam frases de efeitos, bem como de soluções teóricas prontas como se uma mesma configuração se aplicasse a todas as pessoas e empresas.

Tendo isso em vista e a fim de compreender o impacto desse novo agente no ambiente empreendedor, a próxima seção discute as principais considerações do assunto no meio acadêmico. 


\subsection{EMPREENDEDORISMO DE PALCO}

Para que seja possível iniciar uma discussão sobre "empreendedorismo de palco", fazse necessário buscar algumas causas que apontem para o surgimento de tal fenômeno. Nesse sentido, Dias e Wetzel (2010) indicam que épocas em que há o aumento do desemprego são também épocas capazes de impulsionar o indivíduo a criar novas possibilidades de sobrevivência, e ao fazer isso, a partir de ideias inovadoras e inventivas, pode alavancar a economia de um País.

No Brasil, de acordo com dados do Instituto de Pesquisa Econômica Aplicada (IPEA, 2019 citado por Lameiras, Corseuil, Ramos, \& Carvalho, 2019) o mercado de trabalho segue bastante deteriorado, permeado por altos contingentes de desocupados, desalentados e subocupados. E essa conjuntura de incertezas e mudanças, bem como as exigências feitas às pessoas que se encontram no mercado de trabalho ou à procura de ingressar nele têm gerado uma grande ansiedade para que 0 indivíduo se mantenha funcional e apto ao mercado (Wood \& Paula, 2001).

Tempos de turbulência política e econômica geram sentimentos de medo, instabilidade e insegurança à população, que busca maneiras de se sustentar (Prates, Santos, Martins, Martins, \& Couto, 2018). Assim, diante da situação econômica e do mercado de trabalho do País, os benefícios advindos do empreendedorismo tornaram-se bastante difundidos por diversas agências, além dos programas de incentivos governamentais (Dias \& Wetzel, 2010).

A ideia de empreendedorismo fornece um meio de entender e participar de um tempo de mudanças e agitação (Chua, 2018). Dessa forma, são exaltadas as iniciativas particulares de cada pessoa na busca de abrir um negócio, ou a dedicação a qualquer atividade autônoma que lhe possibilite ser "patrão de si mesmo" (Chua, 2018; Dias \& Wetzel, 2010).

Todo o contexto de turbulência e competição contribuiu, então, para a geração de uma literatura orientada para questões voltadas às ansiedades e dilemas característicos dos profissionais de Administração: uma literatura de pop-management, na qual o conteúdo perpassa por alguns padrões, como relatos de feitos heroicos, exaltação de novas tecnologias gerenciais e conselhos para que as pessoas alcancem sucesso profissional (Wood \& Paula, 2006), em que, para Rampazo (2015), "o sucesso profissional carrega sentido de alto status social" (p.600). Outro aspecto abordado na literatura do management está na apresentação do empreendedorismo como comportamento e atitude pessoal, que deve extrapolar o mercado de trabalho e atingir outras esferas sociais (Dias \& Wetzel, 2010).

Wood e Paula (2001) comentam que, "Atordoados pelas exigências e pela velocidade em que tudo parece mudar, os indivíduos, assim como as organizações, buscam referências que possam conduzi-los com segurança ao êxito" (p. 8). Assim, há uma concepção de que 
- empreendedorismo pode ajudar a sanar diversos problemas atuais, do desemprego à infelicidade, passando pela crise de valores, em que tudo pode ser solucionado diante da prática empreendedora, que busca combinar plano de negócios, psicologia positiva e inspiração (Casaqui, 2017).

Essas narrativas são empregadas como autoajuda, tendo em grande parte dos casos a intenção de orientar as pessoas sobre uma forma mais acertada de enfrentar as dificuldades que se apresentam e alcançar sucesso (Motta, Corá, \& Mendes, 2019). Dessa forma, de acordo com Duarte e Medeiros (2016), nas organizações as histórias e fantasias de heroísmo estão cada vez mais comuns, servindo como uma válvula de escape para aliviar tensões, enquanto serve de guia para que decisões sejam tomadas em carreiras voltadas para a área dos negócios.

O culto ao empreendedorismo surge em um contexto no qual há uma grande valorização de receitas prontas oferecidas pelo mercado de soluções gerenciais, criando assim um novo imaginário (Wood \& Paula, 2001). Prates et al. (2018) também apontam que há uma grande busca por fórmulas de excelência que possibilitem os indivíduos a alcançarem o sucesso profissional.

Na visão de Dias e Wetzel (2010), essas receitas apresentam um determinado tipo de conteúdo, em que há a responsabilização pessoal dos indivíduos por sua situação profissional e financeira, independente se essa situação seja de empregado ou desempregado, sucesso ou fracasso, sobrevivência ou falência de seu negócio. Assim, o sucesso ou o fracasso não mais se configuram como uma condição de diferença social ou de poder estatal, mas como uma questão de capacidade e desejo individual (Szeman, 2015).

Segundo Duarte e Medeiros (2016), no decorrer da história a visão de um homem com deveres foi modificada para a de um homem que se autorrealiza, sendo, assim, responsável por seu próprio caminho e pelo impacto que causa no ambiente em que está inserido. Constrói-se, então, a imagem de um indivíduo ambicioso, persistente, realizador e que está em uma busca constante pelo sucesso pessoal (Rampazo, 2015).

Motta et al. (2019) compartilham dessa visão e apontam que uma vez que essas receitas estão alinhadas com o modelo tradicional de administração, os profissionais são responsabilizados para que busquem atingir alguma meta, de forma que é evidenciado que somente por meio de um desempenho exemplar de suas atribuições é que uma trajetória de conquista se apresentará. Liga-se então a imagem de uma pessoa realizada a alguém que obteve conquistas por meio do trabalho (Rampazo, 2015).

Assim, torna-se acessível o conhecimento de características gerencialistas por um amplo público que busca "receitas prontas", sem buscar por uma reflexão crítica, para que seja possível construir uma visão emancipada, com diferentes pontos de vista, contradições e conflitos (Motta et al., 2019). O "empreendedorismo de palco" surge por meio de conselhos, 
dicas e expressões de efeito que pouco estão atreladas a condições práticas, mas que possuem uma forte carga sentimental, fazendo alusão ao potencial infinito de ação e imaginação que sujeitos engajados devem possuir para se tornarem empreendedores de sucesso (Faria, 2018).

O empreendedorismo de palco é hoje uma indústria que mobiliza composto formado por setores do entretenimento, mídia e mercado editorial voltada para comercializar palestras, livros, vivências corporativas e todo tipo de conteúdo motivacional que tem como objetivo fomentar o comportamento empreendedor junto a um público leigo no Brasil. (Faria, 2018, p. 111).

As ideias difundidas têm ganhado a força de dogma, uma vez que não há grandes questionamentos sobre sua validade, e há uma forte tendência em acreditar na sua universalidade (Wood \& Paula, 2001). Dessa forma, por não haver questionamentos, a cultura do empreendedorismo tem apresentado contornos de ideologia, e por essa razão há poucas reflexões sobre suas consequências na vida social, organizacional e pessoal, além de coibir a realização de críticas a respeito do significado de sua hegemonia (Wood \& Paula, 2001). Chua (2018) pontua que o empreendedorismo opera com meios ideológicos, visto que oferece um senso de agência e atividade criativa, bem como a possibilidade de criação de riqueza em uma era de precariedade.

Quando se trata da difusão do empreendedorismo, os meios de comunicação (Dias \& Wetzel, 2010), como palestras veiculadas pela internet, blogs de autoajuda, empreendimentos sociais, propostas educacionais, entre outras possibilidades (Casaqui, 2017), são ferramentas estratégicas que têm difundido certa lógica e pacotes gerenciais, popularizando o mundo dos negócios e do management (Dias \& Wetzel, 2010).

Nesse ponto, destaca-se o papel da internet como meio de comunicação de difusão desses conceitos. Plataformas como Instagram, Facebook e YouTube são veículos nos quais é facilitado o encontro de empreendedores elou supostos empreendedores com pessoas dispostas a seguirem seus ensinamentos. Discursos que antes eram restritos a livros e revistas atualmente conseguem uma enorme abrangência. De acordo com Casaqui (2017), "os processos comunicacionais que difundem essa cultura são essenciais no projeto da sociedade empreendedora e seus enquadramentos, suas formas de convocação, suas propostas de engajamento dos indivíduos" (p. 15).

Ao analisar diversos trabalhos a respeito dessa temática, Duarte e Medeiros (2016) entendem que nesses discursos há uma simplificação de conceitos complexos, deixando a entender, muitas vezes de forma errônea, que a partir do esforço empregado os resultados serão positivos. Além disso, oculta-se que grande parte dos empreendedores vêm de posições privilegiadas, em que normalmente possuem acesso a um capital e/ou a redes de contatos 
que colaboram para o êxito de suas atividades (Chua, 2018). Assim, pode-se dizer que os discursos são alienantes e que precisam ser utilizados com cautela (Duarte \& Medeiros, 2016).

Diante do exposto, busca-se a análise do fenômeno por meio de reportagens da web. Procurando descrever como o estudo foi conduzido, apresenta-se na seção seguinte os procedimentos metodológicos realizados.

\section{PROCEDIMENTOS METODOLÓGICOS}

O presente estudo é caracterizado como uma pesquisa qualitativa exploratória. É qualitativa pois se busca conhecer, por meio de reportagens publicadas na web, em sites brasileiros, o que tem sido abordado sobre o fenômeno "empreendedorismo de palco". Assim, de acordo com Godoy (1995), a pesquisa qualitativa não possui preocupação em enumerar elou medir os eventos estudados, nem conta com procedimentos estatísticos para analisar os dados obtidos. Ainda de acordo com a autora, as questões e os focos de interesse podem se apresentar de maneira mais ampla e irem se definindo conforme o estudo é desenvolvido.

É também uma pesquisa exploratória, pois de acordo com o objetivo apresentado, pretende-se investigar esse fenômeno para que se possa compreender melhor sobre ele. Pesquisas exploratórias buscam aprimorar ideias ou descobrir intuições a respeito de determinado fenômeno, de forma que seja possível adquirir mais familiaridade com o problema, com a intenção de fazer com que este se apresente de maneira mais evidente (Gil, 2002).

Dito isso, para a elaboração da pesquisa, foram selecionados os endereços eletrônicos que contivessem no título ou em seu texto o termo "empreendedorismo de palco". Optouse por não buscar outros termos, visto que não há sinônimos que possam corresponder exatamente ao fenômeno que se buscou estudar, além de que, entendeu-se que a busca de outros termos poderia comprometer os resultados obtidos.

Para essa seleção, utilizou-se como ferramenta de busca o Google, através de um browser neutro. Este se configura como um navegador que não utiliza dados armazenados anteriormente, como histórico de atividades, downloads e cookies. A utilização do browser neutro se mostrou pertinente para que o resultado apresentado não fosse comprometido por buscas anteriores realizadas medinante esse mesmo navegador. Para a realização da busca, foi feito também um recorte temporal, buscando constituir o corpus para análise com 
as reportagens mais recentes. Dessa forma, foram selecionados os 20 primeiros endereços eletrônicos apresentados pela ferramenta de busca, entre os anos de 2016 a 2019.

A opção de selecionar os 20 primeiros endereços eletrônicos está ligada a dois fatores: analisar as reportagens mais relevantes e evitar a inclusão de sites que não estivessem destinados à publicação de reportagens. Com relação a esse segundo fator, durante a realização das buscas, percebeu-se que a partir do $20^{\circ}$ resultado a obtenção de links dessa natureza aumentava consideravelmente.

Em um primeiro momento, obtiveram-se, então, 80 endereços eletrônicos que continham o termo "empreendedorismo de palco". Contudo, para uma melhor utilização dos critérios e ferramentas de análise como forma de proporcionar rigor metodológico do trabalho, optou-se somente por trabalhar com as reportagens de blogs ou de sites jornalísticos. Logo, eliminaram-se da amostra informações sobre o tema que foram publicadas no Twitter, Facebook, podcasts, fóruns de discussão e vídeos do YouTube. Também foram eliminadas reportagens repetidas, pois foi identificado que havia reportagens repostadas em diferentes endereços eletrônicos e em data posterior à primeira encontrada. Após essa etapa, o número de reportagens foi reduzido para 60.

Assim, foi realizada a primeira leitura do material coletado, na qual foi possível perceber que algumas das reportagens tratavam de assuntos que não condiziam com o tema da pesquisa, e que, por algum motivo, apenas possuíam o termo citado no corpo do texto, sem apresentar maiores aprofundamentos. Eliminou-se, então, as reportagens em que acontecia esse fato, pois não se justificaria a utilização destas. Posto isso, o número final de reportagens analisadas foi de 34 . A Tabela 1 apresenta as etapas realizadas para a coleta de dados:

Tabela 1

Etapas da coleta de dados

\begin{tabular}{ll}
\hline \multicolumn{1}{c}{ Etapas } & \multicolumn{1}{c}{ Coleta de dados } \\
\hline Browser de busca & Navegação oculta \\
Ferramenta de busca & Google \\
Termo de busca & "Empreendedorismo de palco" \\
Recorte temporal & 1 de janeiro de 2016 a 31 de agosto de 2019 \\
Data de coleta & 7 de setembro de 2019 \\
Tabulação & Título da reportagem, site, autor (se houvesse especifica- \\
Endereços selecionados & do), data e link da reportagem \\
Após a primeira exclusão & 80 \\
Após a segunda exclusão (número final de & 60 \\
reportagens analisadas) & 34 \\
Categorização dos dados & Categorias emergentes dos dados \\
\hline Análise dos dados & Análise de conteúdo \\
\hline
\end{tabular}


Para analisar os dados obtidos foi utilizada a técnica de análise de conteúdo, seguindo os preceitos de Bardin (1977). Dessa forma, dividiu-se a análise em três etapas: pré-análise; exploração do material; tratamento dos resultados obtidos e interpretação. $\mathrm{Na}$ fase da pré-análise foi feita uma leitura flutuante das reportagens selecionadas, buscando uma maior interação com o corpus obtido, bem como identificadas possíveis categorias, uma vez que todas emergiram dos dados. As categorias de análise foram: definições sobre empreendedorismo de palco; falsas promessas; empreendedorismo como autoajuda; indústria do sonho; e foco para ferramentas concretas.

Apresenta-se na Tabela 2 a elucidação de como as categorias foram definidas:

Tabela 2

Elucidação a respeito das categorias de análise

\begin{tabular}{ll}
\hline Categorias de análise & Explicação \\
\hline Empreendedorismo de palco & $\begin{array}{l}\text { Categoria emergida dos dados, visto que as reportagens buscavam em } \\
\text { um primeiro momento definir o que seria o fenômeno. }\end{array}$ \\
\hline Falsas promessas & $\begin{array}{l}\text { Categoria emergida dos dados, dadas as abordagens voltadas para a } \\
\text { observação de que são realizadas promessas no "empreendedorismo de } \\
\text { palco" que não se concretizam. }\end{array}$ \\
\hline Empreendedorismo como autoa- & $\begin{array}{l}\text { Categoria emergida dos dados, uma vez que as reportagens destacam } \\
\text { o grande conteúdo motivacional do "empreendedorismo de palco" se } \\
\text { assemelhando com conteúdo de autoajuda. }\end{array}$ \\
\hline Indústria do sonho & $\begin{array}{l}\text { Categoria emergida dos dados, pois as reportagens apontam que o "em- } \\
\text { preendedorismo de palco" trabalha com apontamentos voltados para a } \\
\text { realização de sonhos. }\end{array}$ \\
\hline Foco para ferramentas concretas & $\begin{array}{l}\text { Categoria emergida dos dados, visto que as reportagens buscavam } \\
\text { chamar a atenção para o consumo de ferramentas que de fato possam } \\
\text { ajudar quem deseja abrir uma empresa. }\end{array}$ \\
\hline
\end{tabular}

$\mathrm{Na}$ fase de exploração do material, foram realizados recortes e classificação dos trechos das reportagens considerados importantes para o esclarecimento da temática estudada. Esses trechos foram relacionados a partir das categorias criadas na fase de préanálise. Em um último momento, realizaram-se o tratamento e a interpretação dos dados obtidos, em que novamente se fez uma leitura dos trechos alocados dentro de categorias, buscando encontrar relações entre eles, para que fosse possível responder ao objetivo proposto. Destaca-se ainda que a fundamentação teórica foi essencial nesse momento, colaborando na interpretação dos dados.

Dessa forma, chega-se então aos resultados e à discussão do presente artigo, que são apresentados na seção que segue. 


\section{RESULTADOS E DISCUSSÃO}

Para uma melhor apresentação dos resultados obtidos, optou-se por apresentá-los de acordo com as categorias utilizadas na análise: definições sobre empreendedorismo de palco; falsas promessas; empreendedorismo como autoajuda; indústria do sonho; e foco para ferramentas concretas.

\section{I DEFINIÇÕES SOBRE EMPREENDEDORISMO DE PALCO}

Ao analisar as reportagens selecionadas para compor este estudo, foi possível perceber que grande parte delas trazia alguma definição do que seria o "empreendedorismo de palco". Assim, apresentam-se a seguir algumas das definições apresentadas.

Tabela 3

Definição de "empreendedorismo de palco"

Você, como interessado no assunto, já foi em alguma palestra onde o palestrante falou, falou e falou, mas no final das contas não falou nada? Isso é empreendedorismo de palco! [...] A palestra é visualmente bonita, os infinitos slides são todos em um padrão de design invejável e a oratória é impecável, mas, na hora de fazer o balanço do que foi aprendido, todo aquele momento não acrescentou nada. [...] É muito comum que termos técnicos e estrangeirismos sejam usados nesse tipo de evento que beira o espetáculo em forma de palestra, já que eles dão um ar de sofisticação e "profissionalismo" [...] Empreendedorismo de palco não trata de um negócio de sucesso ou não, trata de passar um conteúdo vazio de ideias para as pessoas. (Abrantes, 2016).

Esse tipo de empreendedorismo se caracteriza por projetos vazios em conteúdo e valor, mas com empreendedores midiáticos que parecem se nutrir unicamente de uma vaidade sem fim, alimentados pelas redes sociais e por um público ansioso para encontrar exemplos de sucesso rápido. (Tasic, 2016).

O empreendedorismo de palco é a forma como são denominadas palestras e outras ações realizadas para difundir o empreendedorismo, utilizando técnicas fortemente motivacionais e muitas vezes baseadas em "clichês" como "lute pelos seus sonhos" ou "tudo é possível se você acreditar". E, embora esses não sejam conselhos ruins, são frases bastante desgastadas e que muitas vezes não condizem com a realidade e os desafios que é empreender. (Dias, 2017).

Nota-se nos trechos anteriores que a definição de "empreendedorismo de palco" está relacionada com eventos em que há apelos midiáticos, nos quais o conteúdo é difundido por meio de práticas motivacionais para cativar o público. Essas percepções vão de encontro à definição proposta por Faria (2018), apresentando que o empreendedorismo possui forte apelo motivacional, desenvolvendo essas ideias com um público leigo no Brasil.

Considera-se então que é relevante argumentar sobre a efetividade de tais eventos, palestras e/ou livros, visto que segundo as definições encontradas, os conteúdos divulgados podem ser bastante questionáveis. Com relação a esse aspecto, Wood e Paula (2001) destacam que a cultura do empreendedorismo tem, ao longo do tempo, apresentado alguns aspectos de ideologia. Para Wood e Paula, esses aspectos de ideologia ocorrem pelo fato de 
que há uma inibição de "reflexões mais críticas sobre o significado de sua hegemonia e sobre suas consequências na vida social, organizacional e pessoal" (p. 3).

Percebe-se também, que por meio dos trechos das reportagens, os conteúdos apresentados por empreendedores de palco podem remeter a um sucesso rápido, apresentando discursos que, em muitas das vezes, não condizem com a realidade do mercado e com os reais desafios enfrentados por alguém que deseja se tornar um empreendedor. Isso conduz à próxima seção, que trata das falsas promessas.

\subsection{FALSAS PROMESSAS}

Com relação ao conteúdo que compõe os eventos, palestras e livros realizados por empreendedores de palco, há um alerta, pois o fenômeno é basicamente definido por não apresentar um conteúdo confiável e manter seu foco na parte motivacional.

Se você está pensando em abrir um negócio ou entrar de vez na economia digital, oferecendo produtos ou serviços, ou até mesmo utilizar a internet como poder complementar a um negócio físico que você já possua, tome cuidado! Há uma indústria de falsas promessas e de prosperidade barata, que tentará te capturar. (Carvalho, 2016).

Grande parte das reportagens analisadas, ainda que não possuam trechos específicos, possuem esse tom de alerta, buscando revelar para seus leitores que há de se ter certo cuidado com promessas grandes e que asseguram resultados rápidos.

\footnotetext{
O que é perigoso-e está longe de ser uma característica exclusiva dos empreendedores de palcosão os discursos ingênuos e que incentivam pessoas a assumirem riscos desproporcionais .... Instituir a figura do Empreendedor de Palco teve um papel importante para a identificação de um padrão, mas se prender ao estereótipo e não ao discurso problemático ainda deixa pessoas inocentes vulneráveis. $O$ problema não é o palco, mas a superficialidade do que está sendo dito lá em cima. (Medium, 2018).
}

Exatamente nesse ponto também é realizado um alerta sobre a difusão e reprodução de fórmulas prontas, mostrando que essa forma de se apresentar o conteúdo é um dos pilares do "empreendedorismo de palco". Segundo Wood e Paula (2001), atualmente há um contexto de grande valorização de receitas prontas. 
Tabela 4

Fórmulas prontas

Contudo, no lugar de obras de conteúdo didático, vemos best-sellers que prometem fórmulas para a prosperidade elou ensinar o passo a passo para alcançar o grande sucesso e lições para ter uma visão tão empreendedora quanto Steve Jobs. (Dias, 2017).

Assim, é importante ressaltar que o objetivo destas palestras se alterou com o passar do tempo e, hoje, muitos palestrantes usam esses eventos para vender livros e apresentar um discurso pronto sobre como atingir o sucesso, estipulando uma fórmula mágica, que não retrata o real caminho trilhado pelos empreendedores. (Pet adm Ufc, 2017).

O empreendedorismo se resumiu a slideshow. E o motivo é simples: As pessoas compram o que elas querem ouvir. É nesse momento que o empreendedor de palco cresce. $O$ empreendedorismo de quem, repetindo, nunca empreendeu. Mas sabe te ensinar como conquistar sucesso, fama e dinheiro. E de preferência, rápido, agora! (Fábrica 3, 2019).

Assim, cabe questionar se o conteúdo apresentado por empreendedores de palco é realmente relevante e eficaz. Motta et al. (2019) chamam a atenção para esse aspecto, quando apontam que apesar de tornar acessível o conhecimento sobre aspectos gerencialistas para um grande público, isso acontece por meio da busca desse público por "receitas prontas", o que inviabiliza a busca por uma reflexão crítica. Assim, para os autores, não há a construção de uma visão emancipada, na qual seja possível que diferentes pontos de vista sejam considerados.

Segundo Dias e Wetzel (2010), essas receitas apresentam também um conteúdo que busca responsabilizar os indivíduos por sua condição profissional e financeira, o que também foi encontrado nas reportagens analisadas.

Tabela 5

Responsabilização dos indivíduos

Quando você tenta seguir as dicas de sucesso do empreendedorismo de palco, você se pega perdido porque parece que o erro é seu, a falha é sua quando o objetivo não é alcançado ou a sua história não trilha o mesmo caminho que o palestrante garantiu durante sua apresentação. (Confort, 2016).

O intuito desse post é desafiar o mito propagado atualmente de que o sucesso e, consequentemente o fracasso, dependem apenas do quanto nos achamos merecedores. Lembrem-se que enquanto o seu empreendedor de palco favorito estava alcançando o sucesso, muito mais gente estava falhando, e isso não quer dizer, necessariamente, que eles foram menos "esforçados" ou merecedores. (Eu, Ceo, 2016).

A palavra de ordem é "deixe de ser medíocre" hostilizando quem deseja levar uma vida de poucas ambições e com o foco em outros valores. (Medium, 2018).

Assim, essa visão de responsabilizar o indivíduo por todos os aspectos relacionados ao seu sucesso ou fracasso se estende para além da esfera de empreendedorismo. Dias e Wetzel (2010) apontam que a responsabilização pessoal acontece tanto para pessoas empregadas quanto para desempregadas, e para aquelas que exercem atividades autônomas ou possuem um empreendimento regulamentado. 
Motta et al. (2019) discutem a respeito desse aspecto e apontam que as "receitas prontas" difundidas evidenciam que apenas mediante um desempenho exemplar é que as conquistas serão alcançadas.

\subsection{EMPREENDEDORISMO COMO AUTOAJUDA}

$\mathrm{Na}$ ótica do "empreendedorismo de palco", uma das formas de se apresentar e falar sobre o empreendedorismo está em utilizar fortes apelos motivacionais, chegando a se assemelhar com o conteúdo de livros de autoajuda. Segundo Motta et al. (2019), as narrativas apresentam uma intenção de orientar as pessoas sobre uma forma eficaz de lidar com as dificuldades apresentadas, para que essas pessoas possam alcançar sucesso, porém, são empregadas como autoajuda.

Tabela 7

Empreendedorismo como autoajuda

O discurso de autoajuda, porém, não é escolhido por acaso. Conteúdos motivacionais, que incentivam as pessoas a saírem da sua zona de conforto, fazem muito sucesso e garantem uma legião de fãs aos empreendedores de palco. São cursos, palestras, livros, e-books, posts em redes sociais, presenças em eventos e consultorias que ajudam a movimentar a indústria do empreendedorismo. (Sant'ana, 2016).

A maior crítica ao empreendedorismo de palco é que os conselhos motivacionais e os clichês que apelam para a emoção acabam fazendo com que pessoas inexperientes tenham uma visão equivocada sobre empreendedorismo, entrem no mercado sem nenhum preparo e acabem se tornando números nas estatísticas de falência, o que é muito frustrante e também prejudicial para o cenário empreendedor. [...] Um dos objetivos do empreendedorismo de palco é vender livros, palestras e documentários para auxiliar futuros empreendedores. O problema é quando esse material se limita à autoajuda e oferece pouco ou nenhum conhecimento prático que possa fazer uma real diferença nos negócios. (Dias, 2017).

Muitas vezes, esses profissionais focam mais na parte motivacional do empreendedorismo do que nas ações, podendo fazer com que os alunos consumam muitos conteúdos, porém não cheguem a colocar seus projetos em prática. Isso não significa que você não possa aproveitar nenhuma dica, mas vale ficar atento. (Serasa Experian, 2018)

O problema é que os conteúdos que realmente poderiam ser um oráculo para ajudar alguém a alcançar um objetivo com seu negócio se tornaram conteúdos de autoajuda-que é o que vende-mas não serão essas palavras de incentivo que ajudarão um empreendedor na prática. (Abrantes, 2016).

De acordo com os trechos das reportagens analisadas apresentados anteriormente, é possível perceber que essa forma de passar os conteúdos, utilizada pelos empreendedores de palco, precisa ser tratada com devida atenção, já que o conteúdo prático, que poderia ajudar no alcance de resultados palpáveis para as empresas, acaba sendo trocado por palavras de motivação e incentivo.

Isso corrobora com o que Faria (2018) destacou, apontando que o "empreendedorismo de palco" se apresenta por meio de conselhos, dicas e expressões de efeitos, que pouco contribuem para condições práticas. O conteúdo possui uma forte carga sentimental, 
apresentando que sujeitos engajados, que querem se tornar empreendedores de sucesso, devem ter um potencial infinito de ação e imaginação (Faria, 2018).

Outro ponto a ser destacado quando se trata do fator motivacional apresentado por empreendedores de palco, de acordo com Duarte e Medeiros (2016) são as histórias e fantasias de heroísmo, as quais são tratadas como guia para se tomar decisões em carreiras voltadas para a área dos negócios. Assim, são utilizadas histórias de pessoas que obtiveram sucesso para mostrar que se uma pessoa conseguiu determinado feito, outras também podem conseguir, desconsiderando, assim, diversos outros aspectos que vão além da motivação.

\section{4 "INDÚSTRIA DO SONHO”}

O "empreendedorismo de palco" busca, por meio dos conteúdos difundidos, vender a ideia de uma "indústria do sonho". Assim, o empreendedorismo acaba sendo entendido como uma forma de solucionar problemas pessoais e profissionais. Além disso, é difundida a noção de que toda a trajetória será encantadora.

Tabela 8

Indústria do sonho

A verdade é que o empreendedorismo está virando uma espécie de religião, muitos o veem como a solução para os problemas financeiros, as desavenças com o chefe ou a falta de tempo. Uma visão mais confortável de futuro ou, simplesmente, o único destino possível para alguém tão "brilhante" e destinado ao sucesso total. (Eu, Ceo, 2016).

Esse modelo atrai muitas pessoas que ainda não tiveram uma profunda experiência empreendedora, pois as encanta com um "mundo mágico de sonhos". (Cavalcante, 2016).

O mundo é dos sonhadores! Mas dos sonhadores com pé no chão, com objetivos viáveis e negócios consistentes. O mundo não é cor de rosa. Quanto mais rápido você cair na real, menos frustrante será sua jornada e maiores serão suas chances de sucesso. (Viegas, 2019).

É importante fazer com que o empreendedorismo não se perca no meio dessa fase de glamourização que está acontecendo. É interessante que o assunto tenha ganhado mídia e visibilidade, porém, não se trata de uma vitrine pessoal. (Abrantes, 2016).

Como evidenciado pelo autor Casaqui (2017), há uma busca por combinar o plano de negócios com uma psicologia positiva e inspiração, fazendo com que se conceba o empreendedorismo como uma forma de sanar diversos problemas além do desemprego, como crise de valores e infelicidade.

Dessa forma, a dedicação de uma pessoa, a qualquer atividade autônoma que the traga possibilidades de ser "patrão de si mesmo", é exaltada (Dias \& Wetzel, 2010) como se tudo fosse ser, segundo os trechos supramencionados, um mundo mágico dos sonhos. 


\subsection{FOCO PARA FERRAMENTAS CONCRETAS}

Por fim, muitas das reportagens analisadas discorriam sobre "empreendedorismo de palco" buscando chamar a atenção para que o fato de que empreender requer o domínio e o uso de ferramentas concretas, conhecimento do mercado, experiência e estudo. Chama-se a atenção também para o distanciamento do que é essencial para o empreendedorismo, muito disso por causa do que já foi discutido anteriormente: difusão de "fórmulas prontas", grande foco em aspectos motivacionais e de autoajuda e trabalhar com uma "indústria do sonho".

Tabela 9

Ferramentas concretas

Talvez a essência do empreendedorismo tenha sido tomada pelo empreendedorismo de palco, soluções teóricas que no final das contas não levam empreendedores a lugar nenhum. Mas a prática é muito importante para ter um empreendimento que tenha resultados de verdade. (Abrantes, 2016).

O que vimos até aqui nos mostra que a dedicação por si só não é suficiente para o sucesso. Um cenário econômico favorável e novas tecnologias são apenas alguns exemplos de fatores essenciais para que tudo corra bem. (Eu, Ceo, 2016).

Isso leva muito estudo, prática e, principalmente, testes. Uma coisa que funciona pro meu negócio pode não funcionar no seu. Não existe um padrão ou fórmula do sucesso absoluto. (Blog de Marketing Digital, 2016).

O empreendedorismo real está ligado com causas efetivas, com vivências mais precisas de realidade, com objetivos de mercado mais sólidos, com experiências plenamente palpáveis. Ele foi feito em reposta à vida inconstante, uma espécie de combate contínuo aos obstáculos, uma luta corajosa diante da contrariedade, como uma guerra aos contratempos. Nada é fácil! (Leal, 2018).

Tem diversos empreendedores de sucesso que estão longe dos holofotes. A fama só aparece pra quem busca por ela e isso não quer dizer necessariamente que esta pessoa é um bom exemplo de empreendedoris-

mo. Pode ser apenas um bom motivador. [...] A verdade é que pra aprender a empreender de verdade você vai precisar conhecer gente comum, que está há anos lutando pra fazer seu negócio dar certo. (Santos, 2019).

É possível perceber que os trechos explicitados buscam apontar a importância de se ater a conceitos que realmente refletem a realidade do empreendedorismo, e que possam de fato ajudar as pessoas que se interessam em empreender a obterem um norte e os conhecimentos necessários para dar início à sua jornada, a qual nem sempre dará certo e será completamente exitosa. Ainda é possivel perceber nos trechos um destaque para a importância de se conhecer a vivência de empreendedores reais, que possam contribuir efetivamente na idealização, construção e manutenção de uma empresa.

De acordo com Duarte e Medeiros (2016) é preciso compreender que nos discursos há uma simplificação de conceitos complexos, fazendo com que as pessoas entendam, de forma errônea, que os resultados positivos acontecerão proporcionalmente ao esforço empregado. Assim, é necessário que esses discursos sejam utilizados com cautela (Duarte \& Medeiros, 2016). Apesar de não ter caráter científico, as reportagens que discorrem sobre o "empreendedorismo de palco" entendem que o discurso difundido sobre o empreendedorismo é vago e pouco relevante, quando se considera a criação de empreendimentos reais. 
Após a exposição dos resultados provenientes da pesquisa, apresentam-se as considerações finais do estudo, bem como as contribuições alcançadas e as limitações encontradas.

\section{CONSIDERAÇÕES FINAIS}

O presente artigo buscou mapear, por meio de reportagens divulgadas na internet, em sites brasileiros, o que tem sido abordado sobre o fenômeno do "empreendedorismo de palco". Assim, foi possível perceber que as reportagens analisadas puderam ser divididas em cinco grandes categorias: definições sobre "empreendedorismo de palco", falsas promessas, empreendedorismo como autoajuda, "indústria do sonho" e foco para ferramentas concretas. Ao realizar essa divisão, identificou-se que o evento "empreendedorismo de palco" era definido e constituído, conforme as reportagens analisadas, por diversos aspectos.

Os textos das reportagens convergem no sentido de despertar o leitor para que compreenda que empreender de fato vai muito além do conteúdo difundido pelo "empreendedorismo de palco", por meio de livros, vídeos, palestras, eventos e outros meios de comunicação. Assim, verificou-se que, além das definições apresentadas, em grande parte das reportagens havia um tom de alerta, chamando a atenção dos leitores para o conteúdo veiculado mediante o "empreendedorismo de palco".

Esse conteúdo, de acordo com as reportagens analisadas, deixa de lado dados reais e relevantes para trabalhar com a motivação das pessoas, sendo identificada, inclusive, grande semelhança com temáticas voltadas para a autoajuda. Além disso, trabalha com o sonho das pessoas, com a vontade de que tudo dê certo e de que o sucesso seja alcançado. A partir disso, há grandes possibilidades de que falsas promessas aconteçam, já que o "empreendedorismo de palco" apresenta "receitas prontas", como se ao seguir o que foi prescrito, e com o devido esforço, os objetivos almejados sejam alcançados. Com isso, desconsidera diversos aspectos, como, por exemplo, as especificidades de cada pessoa e de cada empreendimento.

Cabe ressaltar que as reportagens mapeadas coadunam em muitos pontos com as discussões realizadas acerca do assunto pela academia. No que se refere às definições e compreensão do fenômeno, ambas as lentes consideram o "empreendedorismo de palco" um fenômeno sem embasamento prático ou teórico, destacando, ainda, seu apelo motivacional para cativar o público leigo (Dias, 2017; Faria, 2018). No que se refere às falsas promessas do fenômeno, as reportagens fazem alertas e sugerem aos leitores para tomarem atenção com promessas grandes; já os estudos científicos possuem uma abordagem mais profunda, ressaltando como as "receitas prontas" interferem na capacidade de os indivíduos analisarem criticamente as situações (Motta et al., 2019), levando-os a encarar seu fracasso nos negócios ou na vida como uma falha pessoal e intransferível (Dias \& Wetzel, 2010). 
Considerando o fenômeno como um guia de autoajuda, as reportagens destacam que o conteúdo que poderia gerar resultados é deixado de lado, dando lugar aos discursos motivacionais e de incentivo (Abrantes, 2016). A literatura acrescenta, nesse sentido, a utilização de histórias e fantasias de heroísmo (Duarte \& Medeiros, 2016). Assim, o "empreendedorismo de palco" é visto como uma pílula mágica do sucesso não apenas para o mundo dos negócios, mas para muitos aspectos da vida do indivíduo, como concordam muitas reportagens e autores sobre a temática (Casaqui, 2017; Cavalcante, 2016).

Ademais, as reportagens destacam a importância de retornar à atenção aos empreendedores e empreendimentos reais como forma de minimizar essa má-interpretação difundida sobre o empreendedorismo. Nesse sentido, observa-se por parte de alguns autores, como Duarte e Medeiros (2016), a recomendação para agir com cautela diante desses discursos, que são considerados vagos e pouco relevantes ao levarem em conta a criação de empreendimentos reais.

Quando se considera o conhecimento acadêmico a respeito do empreendedorismo, é possível afirmar que este é construído com base em evidências teóricas e empíricas, nas quais se busca conhecer e descrever a realidade encontrada da maneira mais fiel possível. No entanto, com base no que tem sido divulgado por meio do "empreendedorismo de palco", não é passível de afirmação que este possua embasamento teórico-científico. Nesse sentido, pesquisas acadêmicas que busquem desmistificar esses conteúdos, comparando-os com o que é abordado na academia, tornam-se necessárias para que a área de conhecimento não seja acometida por uma banalização.

Como contribuições gerenciais, e, inclusive sociais, fica evidente que é necessário manter ressalvas quanto ao "empreendedorismo de palco", principalmente por este não se basear fundamentalmente em conceitos e ferramentas desenvolvidas mediante pesquisa acadêmica. Como contribuições acadêmicas, o artigo serve como base para que seja considerada uma discussão futura a respeito desses "desvios" do conceito de empreendedorismo, em que seja possível fomentar uma discussão crítica a respeito dessa temática nas esferas socais e gerenciais. Apresenta-se também como um tema relevante para ser discutido nas disciplinas de empreendedorismo dentro das universidades.

A limitação encontrada no estudo está relacionada com a ferramenta de busca utilizada, uma vez que um refinamento mais aprofundado não foi possível ser realizado. Dessa forma, os resultados apresentados continham diversos sites que não eram voltados para a publicação de reportagens, como Twitter, Facebook, podcasts, fóruns de discussão e vídeos do YouTube. Isso ocasionou uma considerável exclusão de material, visto que não se enquadravam no estudo proposto.

Por fim, como pesquisa futura, acredita-se que uma pesquisa voltada para analisar o discurso difundido por "empreendedores de palco" seja de grande valia, uma vez que se 
pode identificar de forma mais profunda se esse discurso corresponde ao que foi abordado nas reportagens aqui analisadas, podendo, inclusive, trazer novos aspectos e abordagens para a discussão, como, por exemplo, os impactos de ideologia do empreendedorismo na sociedade moderna.

\section{REFERÊNCIAS}

Bardin, L. (1977). Análise de conteúdo. Lisboa: Edições 70.

Baron, R. A., \& Shane, S. A. (2007). Empreendedorismo: Uma visão do processo. São Paulo: Thompson Learning.

Blog de Marketing Digital. (2016). Sobre empreendedores de palco, gurus e algumas verdades inconvenientes. Recuperado de https://blogdemarketingdigital.com.br/sobre-empreendedores-de-palco-gurus-e-algumas-verdades-inconvenientes/

Brito, A. M., Pereira, P. S., \& Linard, A. P. (2013). Empreendedorismo. Juazeiro do Norte: Instituto Federal de Educação, Ciência e Tecnologia do Ceará.

Carvalho, I. de. (2016). Por que a indústria do empreendedorismo de palco irá destruir você. Recuperado de https://medium.com/o-novo-mercado/porque-a-ind\%C3\%BAstria-do-empreendedorismo-de-palco-ir\%C3\%Al-destruir-voc\%C3\%AA-3e18309ab47f

Carvalho, J. L. F., Carvalho, F. A. A., \& Bezerra, C. (2010). O monge, o executivo e o estudante ludibriado: Uma análise empírica sobre leitura eficaz entre alunos de administração. Cadernos Ebape.br, 8(3), 535-549.

Casaqui, V. (2017). Abordagem crítica da cultura da inspiração: Produção de narrativas e o ideário da sociedade empreendedora. E-Compós, 20(2).

Cavalcante, A. (2016). Empreendedorismo de palco x empreendedorismo pé no chão. Recuperado de https://administradores.com.br/artigos/empreendedorismo-de-palco-x-empreendedorismo-pe-no-chao

Chiavenato, I. (2012). Empreendedorismo: Dando asas ao espírito empreendedor. Barueri: Manole.

Chua, C. (2018). Innovation, entrepreneurship, and the spirit of digital capitalism. CLCWeb: Comparative Literature and Culture, 20(6), 1-10. 
Collins, D. (2012). In search of popular management: Sensemaking, sensegiving and storytelling in the excellent project. Culture and Organization, 19(1), 42-61.

Confort, M. (2016). Por que você deve ter cuidado com o empreendedorismo de palco. Recuperado de https://manualdohomemmoderno.com.br/comportamento/por-que-vocedeve-ter-cuidado-com-o-empreendedorismo-de-palco

Costa, A. M. da., Barros, D. F., \& Martins, P. E. M. (2012). A alavanca que move o mundo: O discurso da mídia de negócios sobre o capitalismo empreendedor. Cadernos Ebape. br, 10(2), 357-375.

Dias, L. (2017). O que é empreendedorismo de palco? Recuperado de https://administradores.com.br/artigos/o-que-e-empreendedorismo-de-palco

Dias, V. T., \& Wetzel, U. (2010). Empreendedorismo como ideologia: Análise do enfoque da revista Exame em dez anos de publicação (1990-99)*. Revista de Ciências Humanas, 44(1), 97-118.

Dornelas, J. C. A. (2005). Empreendedorismo: Transformando ideias em negócio. Rio de Janeiro: Elsevier.

Dornelas, J. C. A. (2008). Empreendedorismo: Transformando ideias em negócios. Rio de Janeiro: Elsevier.

Drucker, P. F. (1985). Innovation and entrepreneurship: Practice and principles. New York: Harper \& Row.

Duarte, M. P. F. C., \& Medeiros, C. R. de O. (2016). Pop-management: Sorte ou revés? Análise das lições de autoajuda na orientação de gestores e executivos. Revista Gestão $\&$ Conexões, 5(1), 67-89.

Eu, Ceo. (2016). Empreendedorismo de palco. Recuperado de http://www.euceo.com.br/inovacao/empreendedorismo-de-palco/

Fábrica 3. (2019). Não preciso de um coach. Recuperado de http://fabrica3.com.br/nao-preciso-de-um-coach/

Faria, L. S. P. de. (2018). O poder dos sonhos: Uma etnografia de empresas startup no Brasil e no Reino Unido (Tese de doutorado). Universidade Federal do Rio Grande do Sul, Porto Alegre. 
Franco, J. O. B., \& Gouvêa, J. B. (2016). A cronologia dos estudos sobre o empreendedorismo. Revista de Empreendedorismo e Gestão de Pequenas Empresas, 5(3), 144-166.

Galvão, N. D., \& Marin, H. de F. (2009). Técnica de mineração de dados: Uma revisão da literatura. Acta Paulista de Enfermagem, 22(5), 686-690.

Gartner, W. B. (1985). A conceptual framework for describing the phenomenon of new venture creation. Academy of Management Review, 10(4), 696-706.

Gil, A. C. (2002). Como elaborar projetos de pesquisa. São Paulo: Atlas.

Global Entrepreneurship Monitor. (2015). Empreendedorismo no Brasil: Relatório Executivo. Instituto Brasileiro da Qualidade e Produtividade (IBPQ) e SEBRAE. Recuperado de https://bibliotecas.sebrae.com.br/chronus/ARQUIVOS_CHRONUS/bds/bds.nsf/ c6de907fe0574c8ccb36328e24b2412e/\$File/5904.pdf

Global Entrepreneurship Monitor. (2017). Empreendedorismo no Brasil: Relatório Executivo. Instituto Brasileiro da Qualidade e Produtividade (IBPQ) e SEBRAE. Recuperado de https://m.sebrae.com.br/Sebrae/Portal\%20Sebrae/Anexos/Relat\%C3\%B3rio\%20Executivo\%20BRASIL_web.pdf

Godoy, A. S. (1995). Introdução à pesquisa qualitativa e suas possibilidades. Revista de Administração de Empresas, 35(2), 57-63.

Lameiras, M. A. P., Corseuil, C. H. L., Ramos, L. R. A., \& Carvalho, S. S. de. (2019). Mercado de trabalho. Recuperado de http://www.ipea.gov.br/cartadeconjuntura/index.php/tag/ taxa-de-desemprego/

Leal, M. (2018). Empreendedorismo não se faz (só) no palco! Recuperado de https://comunidade.rockcontent.com/empreendedorismo-nao-se-faz-no-palco/

Martes, A. C. B. (2010). Weber e Schumpeter: A ação econômica do empreendedor. Revista de Economia Política, 30(2), 254-270.

McClelland, D. C. (1972). A sociedade competitiva: Realização e progresso social. Rio de Janeiro: Expansão e Cultura.

Medium. (2018). O problema não é o empreendedorismo de palco. Recuperado de https:// medium.com/startup-da-real/o-problema-n\%C3\%A3o-\%C3\%A9-o-empreendedorismo-depalco-9cb278bb7d4d 
Motta, R., Corá, M., \& Mendes, S. (2019). Suor, superação e a medalha: Uma análise do discurso sobre a literatura pop management inspirada no esporte de competição. Revista Brasileira de Estudos Organizacionais, 6(1), 77-101.

Pet Adm Ufc. (2017). Empreendedorismo de palco ou palestra de autoajuda? Recuperado de http://www.petadm.ufc.br/?p=3233

Portier, J. P., \& Tiran, A. (2009). The Edition of the Complete Works of Jean-Baptiste Say. Cahiers d'économie politique/Papers in Political Economy, 57, 151-173.

Prates, R. G. S. P. G., Santos, I. L., Martins, J. N., Martins, F. S. A., \& Couto, F. F. (2018). No-value generation? Success is an 'exact science' that everyone can learn! Revista de Administração Mackenzie, 19(2), 1-26.

Rampazo, A. V. (2015). O management e o projeto de controle do mundo. Farol-Revista de Estudos Organizacionais e Sociedade, 2(4), 591-641.

Sant'ana, J. (2016). Atenção: Empreendedores de palco se disseminam na base da autoajuda. Recuperado de https://www.gazetadopovo.com.br/economia/empreender-pme/atencao-empreendedores-de-palco-se-disseminam-na-base-da-autoajuda-a2btttvilnuum70tgcma4vxfr/

Santos, E. D. dos, \& Freitas, E. C. de. (2017). Imagens de si no discurso: cenografias e ethé discursivos da empreendedora Bel Pesce na Web. Animus-Revista Interamericana de Comunicação Midiática, 16(32), 114-128.

Santos, G. (2019). Empreendedorismo Nutella: Muito palco e Power Point e pouco suor no balcão. Recuperado de http://www.guisantospro.com/empreendedorismonutella/

Serasa Experian. (2018). O que é empreendedorismo? Definição e dicas para quem quer ser um! Recuperado de https://empresas.serasaexperian.com.br/blog/o-que-e-empreendedorismo-definicao-e-dicas-para-quem-quer-ser-um/

Szeman, I. (2015). Entrepreneurship as the new common sense. South Atlantic Quarter$l y, 114(3), 471-490$.

Tasic, I. (2016). Não seja um empreendedor de palco. Recuperado de https://revistapegn. globo.com/Colunistas/lgor-Tasic/noticia/2016/10/nao-seja-um-empreendedor-de-palco. html

Tonelli, D. F., Brito, M. J. de., \& Zambalde, A. L. (2011). Empreendedorismo na ótica da teoria ator-rede: Explorando alternativa às perspectivas subjetivista e objetivista. Cadernos Ebape.br, 9(SPE1), 586-603. 
Viegas, R. (2019). Chega de empreendedorismo de palco e coaches! Recuperado de https:// www.renanviegas.com.br/chega-de-empreendedorismo-de-palco-e-coaches/

Wood, T., Jr., \& Paula, A. P. P. de. (2006). A mídia especializada e a cultura do management. Organizações \& Sociedade, 13(38), 91-105.

Wood, T., Jr., \& Paula, A. P. P. de. (2001). Pop-Management. Anais do Encontro Nacional da Anpad, Campinas, 25.

\section{Como citar este artigo:}

\section{ABNT}

SANTOS, Lauriene Teixeira et al. Receitas a serem seguidas? Mapeamento sobre o fenômeno "empreendedorismo de palco" em reportagens da web. RACE, Revista de Administração, Contabilidade e Economia, Joaçaba: Editora Unoesc, v. 19, n. 2, p. 335-360, maio/ago. 2020. Disponível em: http://editora.unoesc.edu.br/index.php/race. Acesso em: dia/ mês/ano.

\section{APA}

Santos, L. T., Becheri, J. de O., Oliveira, I. R. e G. de; \& Leme, P. H. M. V. (2020). Receitas a serem seguidas? Mapeamento sobre o fenômeno "empreendedorismo de palco" em reportagens da web. RACE, Revista de Administração, Contabilidade e Economia, 19(2), 335-360. Recuperado de http://editora.unoesc.edu.br/index.php/race 
